\section{ANALISIS TINGKAT SUKU BUNGA BI TERHADAP JUMLAH SIMPANAN YANG DAPAT DIHIMPUN Studi Kasus Terhadap Deposito Berjangka Rupiah (Pada Bank Umum di Indonesia)}

\author{
Moch. Arifin dan Rianika Gedriana \\ Program Studi Manajemen, Sekolah Tinggi Ilmu Ekonomi Kesatuan \\ Bogor, Indonesia \\ Email : lemlit@stiekesatuan.ac.id
}

BI Rate,

Deposits

015

Submitted: JANUARI 2016

Accepted: FEBRUARI 2016

Indonesian Banking is currently experiencing significant growth, when seen from fund collections, fund management and credit allocations. A bank's main function has the obligation to collect funds, one of which is through current accounts. This is a relatively easy method in collecting third party's funds. The research is aimed to uncover the link of BI rate with the rupiah allocation of fund in Indonesian banks, and how far it is affecting the decision of savings and current accounts. This study is conducted using descriptive and quantitative analysis of the data obtained from Bank of Indonesia statistics. The results show. The results using the correlation method for one-month rupiah deposits, $r=-0.2384$, 3-month rupiah deposits, $r=-0.6108$, 6-month rupiah deposits, $r=-0.1615$, and for rupiah deposits 12 months, $r=0,9775$ this show that $r=-0$, the relationship $x$ and $y$ is negative and very strong (the opposite relationship $x$ and $y$ ). However, when looking for savings by the method of research the results of correlation $r=-0.795$, indicating that the relationship $x$ and $y$ is also negative and very strong. From the analysis of hypothesis testing (Test T) obtained T calculated for each deposit period is 0.8852 (one month), - 0.0069 (3 months), -0.0102 (6 months), -0.0259 ( > = 12 months), whereas for savings products $-4,7319$, assuming a $95 \%$ confidence value, then count assessed $T$ is smaller than the T table by 2.16. Where it is indicated that $\mathrm{H}_{0}$ accepted, $\mathrm{Ha}$ rejected the hypothesis stated interest rate does not affect the amount of deposit and savings.

Key word: BI Rate, Deposits.

\title{
PENDAHULUAN
}

Sesuai fungsinya, Bank mengemban kewajibannya untuk menghimpun dana sebagai modal dalam pengelolaan usahanya. Modal inilah yang nantinya akan dikelola dan disalurkan dalam bentuk kredit. Hal ini sangat membantu tentunya dalam menunjang pelaksanaan pembangunan nasional dalam rangka pemerataan pembangunan dan hasil-hasilnya.

Salah satu yang memiliki prospek positif dalam upaya penghimpunan dana adalah deposito. Berdasarkan proporsi total dana yang berhasil dihimpun hingga Desember 2011, deposito memiliki jumlah terbesar yakni sebesar Rp 1.258,12 triliun atau mengalami kenaikan Rp 34,27 triliun (2,80 persen) selama satu bulan terakhir.

Secara umum besaran penetapan bungan deposito ditentukan oleh BI Rate dan maksimum nilai penjaminan yang ditetapkan oleh Lembaga Penjaminan Simpanan (LPS). BI rate adalah suku suku bunga kebijakan yang mencerminkan sikap atau stance kebijakan moneter yang ditetapkan oleh bank Indonesia dan diumumkan kepada publik. Dengan mempertimbangkan faktor-faktor lain dalam perekonomian, Bank Indonesia akan menaikkan BI Rate apabila inflasi ke depan diperkirakan melampaui sasaran yang telah ditetapkan, sebaliknya Bank Indonesia

JIMKES

Jurnal Ilmiah Manajemen Kesatuan Vol. 4 No.1, 2016 pg. $015-021$ STIE Kesatuan
ISSN $2337-7860$ 
BI Rate,

Deposits

akan menurunkan BI Rate apabila inflasi ke depan diperkirakan berada di bawah sasaran yang telah ditetapkan. (www. bi.go.id)

\section{TINJAUAN PUSTAKA}

Beberapa teori yang mendasari penelitian ini diantaranya adalah : pengertian atau definisi Bank menurut Undang-Undang No. 7 Tahun 1992 tentang Perbankan diperbaharui dengan Undang-undang No. 10 Tahun 1998 : "Perbankan adalah segala sesuatu yang menyangkut tentang bank, mencakup kelembagaan,kegiatan usaha, serta cara dan proses dalam melaksanakan kegiatan usahaanya".

Bank merupakan lembaga keuangan dimana kegiatan sehari-harinya adalah dalam bidang jual beli uang. Tentu saja sebelum menjual uang (memberikan pinjaman) bank harus terlebih dahulu membeli uang (menghimpun dana) sehingga dari selisih bunga tersebutlah bank mencari keuntungan. Sumber dana bank dapat diperoleh dari dana yang bersumber dari bank itu sendiri, dana yang berasal dari masyarakat luas, dan dana yang bersumber dari lembaga lainnya. Menurut Kasmir (Kasmir, 2001, 64)

Suku bunga menurut Lipsey, Ragan, Courant (1997:471) : "suku bunga adalah harga yang dibayarkan untuk satuan mata uang yang dipinjam pada periode waktu tertentu".

Pengertian deposito menurut Undang-undang No.7 Tahun 1992 tentang perbankan Indonesia :

"Deposito adalah simpanan masyarakat pihak ketiga kepada bank yang penarikannya hanya dapat dilakukan setelah jangka waktu yang diperjanjikan tiba".

\section{METODE PENELITIAN}

Jenis data yang digunakan penulis dalam melakukan penelitian adalah data kuantitatif yaitu berupa data yang berbentuk angka-angka, sedangkan sumber data yang digunakan adalah data sekunder yang dicatat dari Bank Indonesia pada kurun waktu 2011 sampai dengan 2012.

Sedangkan metode analisis data yang digunakan penulis yaitu dengan metode statistik kuantitatif dan metode analisis deskriptif.

\section{HASIL DAN PEMBAHASAN}

\section{Analisis Tingkat Suku Bunga BI terhadap Jumlah Simpanan yang dapat Dihimpun}

\section{A. Data Deposito}

\section{Tabel 1}

Data deposito berjangka 1 bulan dan suku bunga BI :

\begin{tabular}{|l|l|l|l|l|c|}
\hline \multirow{2}{*}{ Bulan } & \multicolumn{2}{|c|}{ 1 Bulan } & & & \\
\cline { 2 - 6 } & Bunga & \multicolumn{1}{c|}{ Total Deposito } & & & \\
\hline & X1 & \multicolumn{1}{|c|}{ Y1 } & $\mathbf{X 1}^{\mathbf{2}}$ & Y1 $^{\mathbf{2}}$ & X1.Y1 \\
\hline Januari & 6.71 & 574,454 & 45.02 & $329,997,398,116$ & $3,854,586$ \\
\hline Februari & 6.71 & 580,231 & 45.02 & $336,668,013,361$ & $3,893,350$ \\
\hline Maret & 6.82 & 669,049 & 46.51 & $447,626,564,401$ & $4,562,914$ \\
\hline April & 6.80 & 667,987 & 46.24 & $446,206,632,169$ & $4,542,312$ \\
\hline Mei & 6.80 & 665,454 & 46.24 & $442,829,026,116$ & $4,525,087$ \\
\hline Juni & 6.80 & 732,657 & 46.24 & $536,786,279,649$ & $4,982,068$ \\
\hline Juli & 6.81 & 745,897 & 46.38 & $556,362,334,609$ & $5,079,559$ \\
\hline Agustus & 6.77 & 766,357 & 45.83 & $587,303,051,449$ & $5,188,237$ \\
\hline
\end{tabular}




\begin{tabular}{|l|l|l|l|l|l|} 
September & 6.86 & 803,657 & 47.06 & $645,864,573,649$ & $5,513,087$ \\
\hline Oktober & 6.80 & 713,932 & 46.24 & $509,698,900,624$ & $4,854,738$ \\
\hline November & 6.59 & 689,024 & 43.43 & $474,754,072,576$ & $4,540,668$ \\
\hline Desember & 6.41 & 673,472 & 41.09 & $453,564,534,784$ & $4,316,956$ \\
\hline Januari & 6.31 & 634,987 & 39.82 & $403,208,490,169$ & $4,006,768$ \\
\hline Februari & 6.08 & 657,268 & 36.91 & $432,001,223,824$ & $3,992,903$ \\
\hline Maret & 5.76 & 686,881 & 33.18 & $471,805,508,161$ & $3,956,435$ \\
\hline Jumlah & 99 & $10,261,307$ & 655 & $7,074,676,603,657$ & $67,809,666$ \\
\hline
\end{tabular}

Tabel 2

Data deposito berjangka 3 bulan dan suku bunga BI :

\begin{tabular}{|l|l|l|l|l|l|}
\hline \multirow{3}{*}{ Bulan } & \multicolumn{2}{|c|}{ 3 Bulan } & & & \\
\cline { 2 - 6 } & Bunga & $\begin{array}{c}\text { Total } \\
\text { Deposito }\end{array}$ & & & \\
\hline & X2 & Y2 & $\mathbf{X 2}^{\mathbf{2}}$ & \multicolumn{1}{|c|}{$\mathbf{Y 2}^{\mathbf{2}}$} & \multicolumn{1}{|c|}{ X2.Y2 } \\
\hline Januari & 6.96 & 130,879 & 48.44 & $17,129,312,641$ & 910,918 \\
\hline Februari & 6.96 & 132,574 & 48.44 & $17,575,865,476$ & 922,715 \\
\hline Maret & 7.06 & 133,781 & 49.84 & $17,897,355,961$ & 944,494 \\
\hline April & 7.09 & 133,231 & 50.27 & $17,750,499,361$ & 944,608 \\
\hline Mei & 7.09 & 135,829 & 50.27 & $18,449,517,241$ & 963,028 \\
\hline Juni & 7.06 & 140,124 & 49.84 & $19,634,735,376$ & 989,275 \\
\hline Juli & 7.05 & 142,826 & 49.70 & $20,399,266,276$ & $1,006,923$ \\
\hline Agustus & 7.20 & 141,987 & 51.84 & $20,160,308,169$ & $1,022,306$ \\
\hline September & 7.22 & 212,271 & 52.13 & $45,058,977,441$ & $1,532,597$ \\
\hline Oktober & 7.15 & 212,567 & 51.12 & $45,184,729,489$ & $1,519,854$ \\
\hline November & 6.91 & 220,812 & 47.75 & $48,757,939,344$ & $1,525,811$ \\
\hline Desember & 6.76 & 222,076 & 45.70 & $49,317,749,776$ & $1,501,234$ \\
\hline Januari & 6.56 & 226,913 & 43.03 & $51,489,509,569$ & $1,488,549$ \\
\hline Februari & 6.56 & 227,232 & 43.03 & $51,634,381,824$ & $1,490,642$ \\
\hline Maret & 6.33 & 230,827 & 40.07 & $53,281,103,929$ & $1,461,135$ \\
\hline Jumlah & 104 & $2,643,929$ & 721 & $493,721,251,873$ & $18,224,089$ \\
\hline
\end{tabular}

Tabel 3

Data deposito berjangka 6 bulan dan suku bunga BI :

\begin{tabular}{|l|c|c|c|c|c|}
\hline \multirow{2}{*}{ Bulan } & \multicolumn{2}{|c|}{ 6 Bulan } & & & \\
\cline { 2 - 6 } & Bunga & $\begin{array}{c}\text { Total } \\
\text { Deposito }\end{array}$ & & & \\
\hline & $\mathbf{X 3}$ & $\mathbf{Y 3}$ & $\mathbf{X 3}^{2}$ & $\mathbf{Y 3}^{\mathbf{2}}$ & $\mathbf{X 3 . Y 3}$ \\
\hline Januari & 7.02 & 66,934 & 49.28 & $4,480,160,356$ & 469,877 \\
\hline Februari & 7.11 & 67,490 & 50.55 & $4,554,900,100$ & 479,854 \\
\hline Maret & 7.17 & 68,209 & 51.41 & $4,652,467,681$ & 489,059 \\
\hline April & 7.18 & 73,634 & 51.55 & $5,421,965,956$ & 528,692 \\
\hline Mei & 7.19 & 75,379 & 51.70 & $5,681,993,641$ & 541,975 \\
\hline Juni & 7.21 & 82,226 & 51.98 & $6,761,115,076$ & 592,849 \\
\hline Juli & 7.11 & 83,990 & 50.55 & $7,054,320,100$ & 597,169 \\
\hline Agustus & 7.07 & 83,334 & 49.98 & $6,944,555,556$ & 589,171 \\
\hline September & 7.22 & 87,534 & 52.13 & $7,662,201,156$ & 631,995 \\
\hline Oktober & 7.22 & 89,990 & 52.13 & $8,098,200,100$ & 649,728 \\
\hline November & 7.21 & 91,234 & 51.98 & $8,323,642,756$ & 657,797 \\
\hline Desember & 7.29 & 90,412 & 53.14 & $8,174,329,744$ & 659,103 \\
\hline Januari & 7.21 & 94,323 & 51.98 & $8,896,828,329$ & 680,069 \\
\hline Februari & 6.96 & 97,323 & 48.44 & $9,471,766,329$ & 677,368 \\
\hline
\end{tabular}


BI Rate,

Deposits
Maret

Jumlah

6.74

6.74

\begin{tabular}{l|l|l}
107 & $1,248,120$ & 762
\end{tabular}

Tabel 4

Data deposito berjangka $>=12$ bulan dan suku bunga BI :

$\underline{018}$

\begin{tabular}{|l|l|l|l|l|l|}
\hline \multirow{2}{*}{ Bulan } & \multicolumn{2}{|c|}{$>$ 12 Bulan } & & & \\
\cline { 2 - 6 } & Bunga & $\begin{array}{c}\text { Total } \\
\text { Deposito }\end{array}$ & & & \\
\hline & $\mathbf{X 4}$ & \multicolumn{1}{|c|}{ Y4 } & \multicolumn{1}{|c|}{$\mathbf{X 4}^{\mathbf{2}}$} & \multicolumn{1}{|c|}{$\mathbf{Y 4}^{\mathbf{2}}$} & X4.Y4 \\
\hline Januari & 7.23 & 70,948 & 52.2729 & $5,033,618,704$ & 512,954 \\
\hline Februari & 7.25 & 71,278 & 52.5625 & $5,080,553,284$ & 516,766 \\
\hline Maret & 7.17 & 73,709 & 51.4089 & $5,433,016,681$ & 528,494 \\
\hline April & 7.14 & 74,530 & 50.9796 & $5,554,720,900$ & 532,144 \\
\hline Mei & 7.10 & 75,290 & 50.41 & $5,668,584,100$ & 534,559 \\
\hline Juni & 7.07 & 78,994 & 49.9849 & $6,240,052,036$ & 558,488 \\
\hline Juli & 7.02 & 80,621 & 49.2804 & $6,499,745,641$ & 565,959 \\
\hline Agustus & 6.97 & 79,620 & 48.5809 & $6,339,344,400$ & 554,951 \\
\hline September & 7.01 & 82,670 & 49.1401 & $6,834,328,900$ & 579,517 \\
\hline Oktober & 6.98 & 85,913 & 48.7204 & $7,381,043,569$ & 599,673 \\
\hline November & 6.95 & 86,309 & 48.3025 & $7,449,243,481$ & 599,848 \\
\hline Desember & 6.87 & 86,704 & 47.1969 & $7,517,583,616$ & 595,656 \\
\hline Januari & 6.77 & 90,781 & 45.8329 & $8,241,189,961$ & 614,587 \\
\hline Februari & 6.75 & 93,103 & 45.5625 & $8,668,168,609$ & 628,445 \\
\hline Maret & 6.68 & 95,579 & 44.6224 & $9,135,345,241$ & 638,468 \\
\hline Jumlah & 105 & $1,226,049$ & 735 & $101,076,539,123$ & $8,560,508$ \\
\hline
\end{tabular}

Tabel 5

Data tabungan bulan dan suku bunga tabungan BI :

\begin{tabular}{|l|l|l|l|l|l|}
\hline \multirow{2}{*}{ Bulan } & \multicolumn{2}{|c|}{ 1 Bulan } & & & \\
\cline { 2 - 6 } & \multirow{2}{*}{ Bunga } & $\begin{array}{c}\text { Total } \\
\text { tabungan }\end{array}$ & & & \\
\hline Januari & \multicolumn{1}{|c|}{ X1 } & \multicolumn{1}{|c|}{ Y1 } & \multicolumn{1}{|c|}{$\mathbf{X 1}^{\mathbf{2}}$} & \multicolumn{1}{c|}{ YI $^{\mathbf{2}}$} & \multicolumn{1}{|c|}{ X1.Y1 } \\
\hline Februari & 2.87 & 54,879 & 8.24 & $3,011,704,641$ & 157,503 \\
\hline Maret & 2.74 & 55,305 & 8.12 & $3,058,643,025$ & 157,619 \\
\hline April & 2.68 & 57,831 & 7.18 & $3,344,424,561$ & 154,987 \\
\hline Mei & 2.69 & 55,884 & 7.24 & $3,123,021,456$ & 150,328 \\
\hline Juni & 2.79 & 56,789 & 7.78 & $3,224,990,521$ & 158,441 \\
\hline Juli & 2.68 & 57,672 & 7.18 & $3,326,059,584$ & 154,561 \\
\hline Agustus & 2.67 & 56,666 & 7.13 & $3,211,035,556$ & 151,298 \\
\hline September & 2.62 & 57,373 & 6.86 & $3,291,661,129$ & 150,317 \\
\hline Oktober & 2.53 & 58,573 & 6.40 & $3,430,796,329$ & 148,190 \\
\hline November & 2.51 & 58,236 & 6.30 & $3,391,431,696$ & 146,172 \\
\hline Desember & 2.44 & 58,181 & 5.95 & $3,385,028,761$ & 141,962 \\
\hline Januari & 2.39 & 60,622 & 5.71 & $3,675,026,884$ & 144,887 \\
\hline Februari & 2.26 & 59,567 & 5.11 & $3,548,227,489$ & 134,621 \\
\hline Maret & 2.13 & 58,234 & 4.54 & $3,391,198,756$ & 124,038 \\
\hline Jumlah & 38.85 & 862,005 & 101.26 & $49,570,903,637$ & $2,228,894$ \\
\hline
\end{tabular}

\section{B. Hasil dan Pembahasan}


Hasil dari penelitian yang telah dilakukan dengan metode korelasi adalah : $\mathrm{r}$ untuk deposito 1 bulan sebesar $r=0,2384, r$ untuk deposito 3 bulan $r=-0,6108, r$ untuk deposito 6 bulan $r=-0,1615$, dan untuk deposito 12 bulan $r=-0,9776$. Nilai $r$ untuk tabungan sebesar $\mathrm{r}=-0,795$. Maka Jika $\mathrm{r}=0$ berarti dua variable tersebut antara $\mathrm{x}$ dan y tidak ada hubungan sama sekali. Jika $\mathrm{r}=1$ berarti hubungan $\mathrm{x}$ dan $\mathrm{y}$ adalah positif dan kuat. Jika $r$ mendekati 0 maka hubungan dua variabel semakin melemah. Jika $\mathrm{r}=-1$ atau mendekati -1 , hubungan $\mathrm{x}$ dan $\mathrm{y}$ adalah negative dan sangat kuat (hubungan $\mathrm{x}$ dan y berlawanan). Hasil yang didapatkan dari analisis ini yaitu $\mathrm{r}=-1$ artinya hubungan $\mathrm{x}$ dan $\mathrm{y}$ adalah negatif dan sangat kuat.

Dari data yang telah ada penulis melakukan uji hipotesis maka nilai yang dihasilkan adalah sebagai berikut :

\begin{tabular}{|c|c|c|c|c|c|}
\hline \multirow{2}{*}{$\begin{array}{c}\text { Point of } \\
\text { View }\end{array}$} & \multicolumn{4}{|c|}{ Value Deposit } & \multirow{2}{*}{$\begin{array}{l}\text { Value of } \\
\text { Saving }\end{array}$} \\
\hline & 1 Month & 3 Month & 6 Month & $>=12$ Month & \\
\hline $\mathrm{b}$ & 0,00000123 & $(0,000004)$ & $(0,000002)$ & $(0,000022)$ & $(0,000109)$ \\
\hline $\mathrm{a}$ & 5,75740279 & 7,567703 & 7,302771 & 8,754728 & 8,831058 \\
\hline$E^{2}$ & $55.048 .513 .773,73$ & $27.697 .214 .736,93$ & $1.561 .625 .584,00$ & $863.462 .429,60$ & $34.062 .302,00$ \\
\hline Ey $^{2}$ & 1,47468333 & 0,969693 & 0,266093 & 0,417693 & 0,635000 \\
\hline Exy & $67.937,94$ & $(100.101,849333)$ & $(3.292,570000)$ & $(18.565,056000)$ & $(3.699,250000)$ \\
\hline Sxy & 0.327089489 & 86,410944 & 8,210673 & 24,424007 & 0,133950 \\
\hline $\mathrm{sb}$ & 0,00000139 & 0,000519 & 0,000208 & 0,000831 & 0,000023 \\
\hline T hitung & 0,88526437 & $(0,006961)$ & $(0,010148)$ & $(0,025868)$ & $(4,731898)$ \\
\hline $\begin{array}{l}\text { Tabel T } \\
\text { Asume } \\
95 \%\end{array}$ & 2,16 & 2,16 & 2,16 & 2,16 & 2,16 \\
\hline $\begin{array}{l}\text { Corelation } \\
\text { Methode }\end{array}$ & 0,24 & $(0,61)$ & $(0,16)$ & $(0,98)$ & $(0,80)$ \\
\hline
\end{tabular}

1. Penempatan jumlah deposito berjangka rupiah selama periode penelitian yaitu 15 bulan dari bulan Januari 2011 sampai dengan bulan Maret 2012 menunjukan kenaikan maupun penurunan pada setiap bulannya, tetapi jumlah penurunan deposito maupun tabungan tidak terlalu signifikan.

2. Dari hasil perhitungan diperoleh hasil $\mathrm{T}_{\text {hitung }}$ lebih kecil dibandingkan dengan $\mathrm{T}_{\text {tabel }}$ yaitu $0,1015<2,16$ maka Ho ditolak, Ha diterima dan hipotesis penelitian yang menyatakan tingkat suku bunga BI terhadap jumlah penempatan deposito berjangka 1 bulan memiliki hubungan signifikan tidak dapat diterima, artinya tidak signifikan. Sedangkan untuk menguji dan mengukur kuat tidaknya pengaruh tingkat suku bunga dengan deposito berjangka 1 bulan dengan metode korelasi, maka diperoleh hasilnya yaitu $r=0,24$ artinya hubungan 2 variabel tersebut semakin melemah.

3. Pada deposito berjangka rupiah 3 bulan dihasilkan $T_{\text {hitung }}$ lebih kecil pula dari $\mathrm{T}_{\text {tabel }}$ yaitu $(0,2378)<2,16$ maka Ho ditolak, Ha diterima dan hipotesis penelitian yang menyatakan tingkat suku bunga BI terhadap jumlah penempatan deposito berjangka 3 bulan memiliki hubungan signifikan tidak dapat diterima. Sedangkan untuk menguji dan mengukur kuat tidaknya pengaruh tingkat suku bunga dengan deposito berjangka 3 bulan dengan metode korelasi, maka diperoleh hasilnya yaitu $r=(0,61)$ artinya hubungan 2 variabel tersebut semakin melemah.

4. Pada deposito berjangka rupiah 6 bulan dihasilkan $T_{\text {hitung }}$ lebih kecil pula dari $\mathrm{T}_{\text {tabel }}$ yaitu $0,1015<2,16$ maka Ho ditolak, Ha diterima dan hipotesis penelitian yang menyatakan tingkat suku bunga BI terhadap jumlah penempatan deposito berjangka 6 bulan memiliki hubungan signifikan tidak dapat diterima. Sedangkan untuk menguji dan mengukur kuat tidaknya pengaruh tingkat suku bunga dengan deposito berjangka 6 bulan dengan metode korelasi, maka diperoleh hasilnya yaitu $r=(0,1615)$ artinya hubungan 2 variabel tersebut semakin melemah. 
BI Rate,

Deposits

$\underline{020}$

5. Pada deposito berjangka rupiah $>=12$ bulan dihasilkan $\mathrm{T}_{\text {hitung }}$ lebih kecil pula dari $\mathrm{T}_{\text {tabel }}$ yaitu $0,1015<2,16$ maka Ho ditolak , Ha diterima dan hipotesis penelitian yang menyatakan tingkat suku bunga BI terhadap jumlah penempatan deposito berjangka $>=12$ bulan memiliki hubungan signifikan tidak dapat diterima. Sedangkan untuk menguji dan mengukur kuat tidaknya pengaruh tingkat suku bunga dengan deposito berjangka $>=12$ bulan dengan metode korelasi, maka diperoleh hasilnya yaitu $r=(0,98)$ artinya hubungan 2 variabel tersebut semakin melemah.

6. Selain itu, penulis menguji dengan produk yang berbeda yaitu tabungan maka diperoleh hasil $\mathrm{T}_{\text {hitung }}$ lebih kecil dari $\mathrm{T}_{\text {tabel }}$ yaitu $0,1015<2,16$ maka Ho ditolak , Ha diterima dan hipotesis penelitian yang menyatakan tingkat sukubunga BI terhadap jumlah penempatan tabungan 1 bulan memiliki hubungan signifikan tidak dapat diterima. Sedangkan untuk menguji dan mengukur kuat tidaknya pengaruh tingkat suku bunga tabungan 1 bulan dengan menggunakan metode korelasi, maka diperoleh hasilnya yaitu $r=(0,795)$ artinya hubungan 2 variabel tersebut semakin melemah.

\section{SIMPULAN}

Berdasarkan hasil penelitian yang telah dilakukan mengenai Analisis Tingkat Suku Bunga BI terhadap Jumlah Simpanan yang dapat Dihimpun pada Bank Umum di Indonesia periode 15 bulan, terhitung sejak tahun 2011 sampai dengan 2012, maka dapat ditarik simpulan sebagai berikut :

1. Penetapan suku bunga merupakan keputusan yang ditetapkan oleh Bank Indonesia, dalam penetapan suku bunga deposito Bank Umum mengacu pada peraturan penetapan suku bunga Bank Indonesia yang dijamin oleh LPS (Lembaga Penjamin Simpanan).

2. Dari hasil yang telah ada maka dapat disimpulkan bahwa $T_{\text {hitung }}$ untuk masingmasing deposito yaitu : $\mathrm{T}_{\text {hitung }}$ deposito 1 bulan sebesar $0,8852, \mathrm{~T}_{\text {hitung }}$ deposito 3 bulan sebesar $-0,0069, \mathrm{~T}_{\text {hitung }}$ deposito 6 bulan sebesar $-0,0102$, dan $\mathrm{T}_{\text {hitung }}$ deposito $>=12$ bulan sebesar $-0,0258$.

3. Nilai $T_{\text {hitung }}$ lebih kecil jika dibandingkan dengan $\mathrm{T}$ maka hasilnya dapat dikatakan tidak signifikan antara tingkat suku bunga BI terhadap penempatan deposito berjangka rupiah. Begitu pula analisis suku bunga BI terhadap deposito menunjukkan hasil yang tidak signifikan. Oleh karena itu dapat dikatakan tidak ada keterkaitan yang positif antara suku bunga BI terhadap jumlah deposito berjangka rupiah.

4. Besar kecilnya penempatan deposito konsumen tidak lagi melihat pada suku bunga yang tinggi tapi dapat disebabkan oleh faktor-faktor lain, diantaranya inflasi dan jumlah pendapatan masyarakat.

\section{DAFTAR PUSTAKA}

Kasmir. 2006. Bank dan Lembaga Keuangan Lainnya. Edisi 6, PT RajaGrafindo Persada, Jakarta.

Taswan. 1997. Akuntansi Perbankan, Transaksi Dalam Valuta Asing, Akademi Manajemen Perusahaan YKPN, Yogyakarta.

Taswan. 2006. Manajemen Perbankan, Konsep Teknik dan Aplikasi. UPP STIM YKPN, Yogyakarta.

Dahlan, Siamat. 2001. Manajemen Lembaga Keuangan. Edisi 3, Fakultas Ekonomi Universitas Indonesia, Jakarta.

Winkel, Chandeni. Analisis Pemberian Kredit dari Simpanan Dana Nasabah Terhadap Pencapaian Profitabilitas. Materi pada Penelitian STIE Kesatuan, Bogor, 11 Desember 2007.

Modul Lembaga Keuangan dan Bank, Sekolah Tinggi Ilmu Ekonomi Kesatuan, Bogor 
Tanjung, Akbar. 2008. Undang-Undang Republik Indonesia Nomor 10 Tahun 1998. http://id.wikisource.org (Diakses 5 September 2011)

Moh. Ramly Faud, dan M.Rustan D.M. 2005. Akuntansi Perbankan. Graha Ilmu, Yogyakarta.

Walpole, Ronald E. 2009. Pengantar Statistika.Edisi 3, PT Gramedia Pustaka Utama, Jakarta.
BI Rate,

Deposits 